Jennifer Hill, UNIVERSITY OF GLOUCESTERSHIRE, jhill18@glos.ac.uk Kathy Berlin, INDIANA UNIVERSITY PURDUE UNIVERSITY INDIANAPOLIS, kberlin@iu.edu Julia Choate, MONASH UNIVERSITY, julia.choate@monash.edu Lisa Cravens-Brown, OHIO STATE UNIVERSITY, cravens-brown.1@osu.edu Lisa McKendrick-Calder, MACEWAN UNIVERSITY, mckendrickl@macewan.ca Susan Smith, LEEDS BECKETT UNIVERSITY, s.v.smith@leedsbeckett.ac.uk

\title{
Can Relational Feed-Forward Enhance Students' Cognitive and Affective Responses to Assessment?
}

\begin{abstract}
Assessment feedback should be an integral part of learning in higher education, but students can find this process emotionally and cognitively challenging. Instructors need to consider how to manage students' responses to feedback so that students feel capable of improving their work and maintaining their wellbeing. In this paper, we examine the role of instructor-student relational feed-forward, enacted as a dialogue relating to ongoing assessment, in dissipating student anxiety, enabling productive learning attitudes and behaviours, and supporting wellbeing. We undertook qualitative data collection within two undergraduate teaching units that were adopting a relational feed-forward intervention over the 2019-2020 academic year. Student responses were elicited via small group, semistructured interviews and personal reflective diaries, and were analysed inductively using thematic analysis. The results demonstrate that relational feed-forward promotes many elements of student feedback literacy, such as appreciating the purpose and value of feedback, judging work against a rubric, exercising volition and agency to act, and managing affect. Students were keen for instructors to help them manage their emotions related to assessment, believing this would promote their wellbeing. We conclude by exploring academic strategies and pedagogies that position relational instructor feedforward as an act of care, and we summarize the key characteristics of emotionally resonant relational feed-forward meetings.
\end{abstract}

\section{KEYWORDS}

assessment feedback, relational feed-forward, thematic analysis, emotional resonance, wellbeing

\section{INTRODUCTION}

The number of undergraduate students in higher education experiencing psychological distress appears to be rising across the globe (Auerbach et al. 2018; Carter et al. 2017; Ferguson 2017). Academic pressure contributes to this distress, particularly associated with university assessments (Barnett 2007). Feedback on assessments should be an integral part of learning in higher education (Hattie and Timperley 2007), but students can find this process challenging (Carless and Boud 2018). Part of the difficulty for students is that their emotional responses can play a significant role in determining how they receive and act on feedback (Pitt and Norton 2017; Ryan and Henderson 2018; Small and Attree 2016). Negative emotions, such as stress and anxiety, can reduce 
students' motivation, self-confidence, and self-esteem (Fong et al. 2019; Kim and Lee 2019), impeding their ability to act on assessment feedback within a task and with reference to subsequent work (Forsythe and Johnson 2017; Winstone et al. 2017). Consequently, instructors (tutors) need to consider carefully how to manage students' responses to feedback so that students feel capable of responding to instructor commentary and learning from it.

Positively, conceptualisations of feedback are increasingly anchored in social constructivist approaches, where students engage in conversation with the instructor and/or their peers (Boud and Molloy 2013; Carless et al. 2011; Nicol 2010). Dialogue between student and instructor can promote not only cognitive sense-making (Carless and Boud 2018), but the foregrounding of affective emotions (Hill et al. 2021a; Ryan and Henderson 2018). In this paper, we acknowledge the emotions that students experience related to assessment feedback and examine the influence of instructorstudent relational feed-forward on students' emotions, learning attitudes, and behaviours. This is one of the first studies to investigate the impacts of instructors and students working together to consciously regulate students' emotions to support positive learning behaviours and wellbeing.

We define relational feed-forward as a dynamic and emergent process that unfolds through social interaction between a student and an instructor, recognizing that there are also valuable interactions between students. Relational feed-forward is essentially a dialogic form of assessment communication through which interpretations are shared, meanings are negotiated, and confusions and expectations are clarified (Ajjawi and Boud 2018; Steen-Utheim and Wittek 2017). Relational feed-forward involves an awareness of the socio-affective context of feedback and a consideration of its impact on the learner (Yang and Carless 2013). It positions instructors to engage with learners, with greater awareness of their own power, positionality, and experience (Schwartz 2017). Relational feed-forward draws on elements of the therapeutic relationship found in health care settings, notably respecting the individual; being receptive to their emotions; and establishing warmth, empathy, genuine interest, and non-judgmental behaviour (Kornhaber et al. 2016). As with clinical settings, the relationship between instructor (clinician) and student (patient) provides the context for securing positive outcomes.

Relational feed-forward is future-oriented (Carless and Boud 2018; Orsmond et al. 2013), referring to instructor commentary that either impacts upon an upcoming assignment, or is given post-assignment with specific direction on how it can be applied to future work (Boud and Molloy 2013; Reimann, Sadler, and Sambell 2019). It forms part of an ongoing relationship between instructor and student in which students are consciously supported to understand their next steps in learning. As such, relational feed-forward draws on many aspects of staff-student partnership (Carless 2020; Hill et al. 2021a).

Student wellbeing is "a sustainable positive mood and attitude, health, resilience, and satisfaction with self, relationships, and experiences, in the educational environment” (DEECD 2010, 1). We view wellbeing as an umbrella term that emanates from the achievement of positive emotions, motivation, and self-regulative and self-efficacious learning behaviours. Psychological research demonstrates that positive emotions facilitate cognition, initiating upward spirals toward increasing emotional wellbeing (Fredrickson and Joiner 2002). This is because positive emotions enhance an individual's belief in their own abilities and students with high self-efficacy for learning are motivated to plan and execute their work to achieve a desired result (Ritchie 2016).

Across the entirety of our research process, from conceptualization, through execution and analysis, to interpretation and communication, we have been mindful to adopt Felten's (2013) principles of good practice for the scholarship of teaching and learning. We have grounded our 
inquiry in the scholarly literature, established a clear research objective to critically interrogate the feelings and attitudes that connect students to learning through assessment, adopted robust research methods that capture and respond to the student voice, and are now making the process and products of our inquiry public to inform practice with global reach.

\section{RESEARCH OBJECTIVE}

Our objective was to assess whether relational feed-forward can mediate the emotions felt by students associated with assessment feedback, prompting their emotions, and learning attitudes and behaviours (especially motivation, self-efficacy, and self-regulation), to change positively, hence supporting wellbeing. We viewed motivation as students' pursuits of learning goals, which can be captured in their efforts to engage in academic tasks (Meyer and Turner 2002); self-efficacy as students' beliefs about their capabilities to accomplish specific tasks (Ritchie 2016); and selfregulation as the ability of students to plan, monitor, and evaluate progress; and to adopt strategic approaches to their learning (Nicol and Macfarlane-Dick 2006).

The research we report here comprises the second phase of a more extensive project. Phase one (Hill et al. 2021b) investigated the nature, strength, and persistence of emotions that undergraduate students experienced in relation to receipt of largely written assessment feedback. We found that many students reported difficulty in receiving and acting upon negative feedback, with their emotional responses tending to reduce their motivation, self-confidence, and self-esteem. Positive feedback, by contrast, validated students' self-worth, but was not always motivational. In this paper, we interrogate the impact of a relational feed-forward intervention on the same students' emotions, attitudes, learning behaviours, and wellbeing, and we offer recommendations for emotionally resonant assessment feedback strategies. Although derived from physically proximate face-to-face communication, our recommendations are also relevant to virtual learning environments.

\section{METHODS}

\section{Sampling framework}

We undertook qualitative data collection over the 2019-2020 academic year, initially within three universities of similar size and mission (one module, i.e., individual unit of study, per institution). This framework represented a convenience sample of modules that were adopting a relational feed-forward intervention. Data were collected longitudinally across the duration of the modules. The first phase of data collection, undertaken as the modules began, elicited 30 student responses from first to final years of undergraduate study, across three different subject areas. The results from this research are already published (Hill et al. 2021b). The second phase of the research, undertaken post-feed-forward intervention as the modules concluded, gathered a further 19 student responses from the first-year health sciences and second-year geography units only (table 1). It is the phase two results that we report here. 
Table 1. Sampling framework

\begin{tabular}{|l|l|l|l|}
\hline University & Level of study & \multicolumn{1}{|c|}{ Module (subject) } & \multicolumn{1}{|c|}{$\begin{array}{c}\text { Sample proportion } \\
\text { (phase two) }\end{array}$} \\
\hline $\begin{array}{l}\text { Indiana University Purdue } \\
\text { University Indianapolis, USA }\end{array}$ & Year 1 & Health sciences & $\begin{array}{l}36 \text { percent (14 from 39 } \\
\text { students) }\end{array}$ \\
\hline $\begin{array}{l}\text { University of the West of England, } \\
\text { UK }\end{array}$ & Year 2 & Geography & $\begin{array}{l}17 \text { percent (5 from 30 } \\
\text { students) }\end{array}$ \\
\hline
\end{tabular}

The academic year 2019-2020 was when COVID-19 arrived on the global stage. The data from the first-year module were gathered in semester one before COVID-19 affected students. The data from the second- and final-year modules were gathered in semester two and, whilst these modules were completed in terms of teaching and feedback delivery before the constraints of the pandemic came into force, our end of unit research interviews occurred as the pandemic took hold. As such, respondent numbers at the end of the module were reduced below what we might have anticipated, and we were unable to secure any responses from the final year students. It can be argued, however, that we have secured data from the formative years of learning in higher education, when instructors most need to understand the cognitive and affective responses of their students to assessment feedback.

\section{Relational feed-forward approaches}

\section{Overview}

The qualitative student responses regarding relational feed-forward pertained to two different assessment activities. In this section, we outline the assessment and feedback approach of each module in turn.

\section{First-year health sciences}

As part of the module assessment, students submitted an electronic personal development plan in two stages: a preliminary portfolio to demonstrate appropriate structure and scope, and a second submission in which students included specific artifacts. Students were told that to receive personal feedback on the assignment between stages one and two (as opposed to only seeing points on the rubric), they could attend a face-to-face, 15-minute appointment with the instructor. Of the 39 students enrolled in the class, all but four attended the one-on-one session. The meetings were purposely friendly, open, and based in dialogue, with the instructor demonstrating a receptive and respectful attitude to work of all standards. The students had seen their grade prior to the meeting without any feedback, and conversation began with why they thought they had earned this grade, referencing the initial assessment rubric. The students were asked how they might change their approach for the final submission and discussion centered around ensuring students had a sound plan of action for revising their portfolios. The students selected when to meet with the instructor, and after this they revised their portfolios before submission for summative grading.

\section{Second-year geography}

The main assessed component of the module was a research essay chosen from a range of titles. Students wrote a considered draft of their essay, which they were encouraged to discuss in an 
individual face-to-face meeting with the instructor. Only two of the 30 students did not attend a session with the instructor. During the meetings, which lasted around 30 minutes, the instructor set the scene for honest feedback interactions, outlining the purpose of the meeting (to enable the practices that lie behind essay writing) and setting expectations for a dialogue focused on learning. Moreover, she purposely positioned herself as an ally alongside her learners, demonstrating respect and empathy. The feed-forward meetings started by asking students to summarize the strengths/weaknesses of their draft, and to grade their work against the assessment rubric. The students received no grade or feedback prior to the meeting. The instructor and student discussed how to discern key aspects of the question, and how to apply appropriate knowledge and skills to generate a more effective answer. Students were encouraged to ask questions throughout, and each session ended with the co-creation of an action plan for improvement. As with the first-year module, the students chose when to undertake the meeting with the instructor, and they were subsequently able to revise their drafts before submission for summative grading.

\section{Nature of the instructor-student dialogue}

The instructor-student dialogue adopted across both modules used questioning and thinking time, with each participant taking turns to speak. The dialogue incorporated a mix of query and advice, praise and critique, and related to cognitive, metacognitive, and affective aspects of learning. Such an active process enabled students to elaborate on their thinking and promoted critical engagement. It prompted students towards personal meaning-making, enabling them to understand their orientation to their work more fully. As the assessed work was ongoing and open to revision, the intent was for students to regard the dialogue as a catalyst to improve their work.

\section{Data collection}

Ethical approval was obtained from all institutions prior to commencement of data collection, covering confidentiality, informed consent, right to withdraw, and personal data security (Hill et al. 2021b). Students across both modules were recruited to one of two data collection activities: small group semi-structured interviews and personal reflective diaries.

The small group semi-structured interviews (of two to five students) were conducted on campus (for first-year students, pre-COVID) or online (for second-year students, during-COVID) at the close of module teaching and after relational feed-forward. A sub-set of the phase one research students took part in phase two, allowing them to reflect on any evolution in their feedback emotions and behaviours. Two small group interviews were convened across each of the two modules, giving a total of four interview sessions that captured the voices of 14 students. All respondents were studying full-time and the majority were female, exaggerating a gender bias in enrolment across the full cohorts. The interviews lasted between 40 and 60 minutes, securing rich student narratives.

The small group interviews were digitally recorded and transcribed verbatim. Thirteen prompt questions were synthesized from the literature and agreed by all authors (appendix 1 ). The questions encouraged the students to reflect in a structured way about if and how relational feedforward impacted their emotions, whether it altered their learning attitudes and behaviours, whether they felt different about the relationship with their instructor after relational feed-forward, whether they believed instructors should help them to manage their feedback-related emotions, and whether this would support their wellbeing. All interviews were conducted by research assistants who did not teach the modules. 
The interview transcripts were analysed inductively using thematic analysis (Braun and Clarke 2013), although the identification of themes was influenced by the research objectives and knowledge of scholarly literature. This interpretive approach afforded the opportunity to understand the emergent subjective meanings articulated by the students and to explore how their experiences and emotions were shaped by the relational encounter with their instructor (Denzin and Lincoln 2011). At the end of the module, post-intervention transcripts were coded manually by a pair of researchers using the constant comparative method (Strauss and Corbin 1994). After additional cross-reading, finalized themes were identified and agreed post-coding. The codes were then shared with a third research team member for final verification and to strengthen analytical reliability.

The second data collection activity was writing personal reflective diaries, captured electronically over the duration of the module in the students' own time. Reflective diaries are a trusted form of data for open, critically self-reflective, and rich qualitative research (Ortlipp 2008). Students were prompted to write in their diaries at the start of the module (examined in phase one of the research) and after relational feed-forward with the instructor (examined here). The diary entries reported in this paper were structured around the same prompt questions used in the small group semi-structured interviews. In total, five diaries were received from students at the end of the firstyear module, after relational feed-forward, but none were received at the close of the second-year module. The diaries varied between one and two pages of text. The respondents were all female, undertaking full-time study, and aged between 18 to early 20s. The identification of themes followed the same process and timescale as for the interview transcripts.

We also asked the instructor on each of the modules to keep a diary outlining how they considered and managed both their students' and their own emotions over the duration of the module. We do not formally analyse their responses here as part of our findings, but we drew on selected diary content to enable us to report on the intentions and actions of the instructors during the one-on-one relational meetings with the students.

\section{Data limitations}

Possible weaknesses in the data arising from interpretation of student self-reporting were described in Hill et al. (2021b). A longitudinal, qualitative research approach resulted in a small sample size. However, many of the themes identified through the coding were also evident in the end of module student evaluations, demonstrating that they were representative of the fuller student cohorts. As with phase one of the research, due to our differing sample sizes, the phase two results might best represent first-year students, but we make no claims as to the generalisability of our findings.

\section{FINDINGS}

Face-to-face dialogic feed-forward was a new form of assessment feedback for the sampled students. Consequently, we examined students' responses to relational feed-forward as an initial encounter in their learning journeys.

\section{Key themes}

Analysis of the small group interviews and diaries led to the identification of six over-arching themes with respect to relational feed-forward and student emotions, learning attitudes and behaviours, and wellbeing. These were: 1) students' emotions as they anticipate instructor commentary; 2) the impact of relational feed-forward on students' emotions; 3 ) students' 
relationships with the instructor; 4) students' assessment attitudes and behaviours; 5) the role of the instructor in managing feedback emotions; and 6) the impact of relational feed-forward on wellbeing. These six themes will now be exemplified using student testimony drawn from both data sources.

Theme 1. Students' emotions as they anticipate instructor commentary

Anticipating instructor feedback made the students feel "anxious" and "nervous" above all other emotions. Receiving commentary was a moment of reckoning for them, offering a judgement about their performance, and the uncertainty associated with this exposed their vulnerability:

I was kind of nervous because I never had the opportunity where a teacher initiated meeting up with you and discussing your assignment. (Year 1)

Ifelt a bit nervous, kind of vulnerable... my tutor was going to judge me and tell me face-to-face what she thought about my work. This opens you to criticism and that's quite scary. (Year 2)

On receiving instructor commentary there were negative feelings of disappointment and embarrassment, when students had done worse than they expected, or positive feelings of relief and happiness as they discovered they had made good progress:

I was disappointed. I didn't realize that I was missing a lot of the assignment. I thought I did well on it, but when I got the feedback I was like "Oh wow, I really messed this one up." (Year 1)

During the meeting I was overjoyed with the feedback I was receiving. It took all my will to not beam with joy... I felt reassured that I was where I was supposed to be. (Year 1)

Theme 2. The impact of relational feed-forward on students' emotions

Talking openly with the instructor about draft work helped the students process and deal with their emotions in a positive manner, both in the short- and long-term:

I felt anxious, but then once I started talking to her, it calmed me. I was like, okay, we're talking about this, we're getting it out in the open, I can improve this. (Year 1)

This assessment prompted me to face my emotions when I usually run away from them. I now know that assessment is emotional and that part of doing well at university is how you cope with the negative emotions and lack of confidence so that you can do your best. (Year 2)

The positive impact on student emotions appeared to derive from six central aspects of the relational feed-forward encounter (table 2). First, the instructors consciously established an open and supportive environment. Students talked about feeling comfortable in conversation with their instructor and they were consequently brave enough to be honest about their understanding and to ask questions to seek clarification (table $2 \mathrm{a}$ and $\mathrm{b}$ ). The meetings reduced confusion and helped students develop positive feelings such as relief and reassurance. Second, students were able to interpret the tone of instructor comments more effectively compared with written comments, gaining real-time clarification (table $2 \mathrm{c}$ and $\mathrm{d}$ ). Third, the feed-forward meetings offered balanced, constructive criticism, helping students to understand the weaknesses in their work and providing 
them with clear direction for improvement, which they found motivational (table 2 e and $\mathrm{f}$ ). Fourth, the feed-forward dialogue linked instructor critique clearly to ongoing work rather than to inherent personal ability, and in particular, the second-year students recognized this and their agency to make improvements (table $2 \mathrm{~g}$ and $\mathrm{h}$ ). Fifth, understanding the assignment process, including the role of instructor commentary on draft work, was important in demonstrating to students that assignments evolve and need re-working to produce high grades (table $2 \mathrm{i}$ and $\mathrm{j}$ ). Knowing they had time to improve in a low-stakes environment was calming and enabling for the students, providing a "safety net" and helping them to develop resilience. Finally, the feed-forward dialogue focused student attention on the assessment rubric and clarified the instructor's interpretation of this rubric (table $2 \mathrm{k}$ and 1 ).

Table 2. Aspects of relational feed-forward that positively impacted student emotions

\begin{tabular}{|c|c|}
\hline $\begin{array}{l}\text { Feed-forward } \\
\text { characteristics }\end{array}$ & Exemplar student quotes \\
\hline $\begin{array}{l}\text { 1. The open and } \\
\text { supportive } \\
\text { environment } \\
\text { prompted } \\
\text { student } \\
\text { questions }\end{array}$ & $\begin{array}{l}\text { (a) "Talking with my instructor helped me to effectively come to conclusions as to what I needed } \\
\text { to do to improve... I could ask questions... I learned more easily." (Year 1) } \\
\text { (b) "The way she explained the purpose of the session as a learning opportunity helped to settle } \\
\text { my nerves and I felt comfortable enough to be honest and to ask questions that I normally } \\
\text { shy away from. I tend to avoid feedback because I am afraid of criticism. But I felt I could be } \\
\text { open in this meeting and ask for help when I didn't understand." (Year 2) }\end{array}$ \\
\hline $\begin{array}{l}\text { 2. Talking } \\
\text { clarified the } \\
\text { tone of } \\
\text { instructor } \\
\text { comments }\end{array}$ & $\begin{array}{l}\text { (c) "It took away the confusion. If I would've gotten that feedback without her explanation, I } \\
\text { would be like, I don't know what I did or where I went wrong." (Year 1) } \\
\text { (d) "You can talk it through with the lecturer... There's a lot of nuances in the way people say } \\
\text { things that you don't pick up from a scribble on a piece of paper." (Year 2) }\end{array}$ \\
\hline $\begin{array}{l}\text { 3. The instructor } \\
\text { offered } \\
\text { constructive } \\
\text { critique, giving } \\
\text { students a sense } \\
\text { of direction }\end{array}$ & $\begin{array}{l}\text { (e) "I felt motivated as she was giving me specific feedback on my work... there was } \\
\text { constructive feedback... it gave me a good idea of where I was at and I knew how to fix it." } \\
\text { (Year 1) } \\
\text { (f) "Before I handed in my work I was a bit stuck. After the meeting I was much more aware of } \\
\text { the things I needed to change. There was a target I was trying to hit and suddenly I could see } \\
\text { a clear path to it. This makes you feel good, kind of capable of doing well." (Year 2) }\end{array}$ \\
\hline $\begin{array}{l}\text { 4. The dialogue } \\
\text { pertained to the } \\
\text { work in } \\
\text { progress rather } \\
\text { than personal } \\
\text { ability }\end{array}$ & $\begin{array}{l}\text { (g) "Having the tutor comments before final grading, I recognize more that it is about the work } \\
\text { and not about me. Because it's in sort of a dynamic process that can still be changed." (Year } \\
\text { 2) } \\
\text { (h) "Being face-to-face, you realize more that it is about each piece of work... When you have a } \\
\text { person going through it and giving you that feedback, you take it a bit better." (Year 2) }\end{array}$ \\
\hline
\end{tabular}




\begin{tabular}{|c|c|}
\hline $\begin{array}{l}\text { 5. The dialogue } \\
\text { directed } \\
\text { student } \\
\text { attention to } \\
\text { assessment as a } \\
\text { process }\end{array}$ & $\begin{array}{l}\text { (i) "Talking to the instructor made me feel emotionally better as I could accurately understand } \\
\text { reasonings and next steps. It helped to build my emotional resilience." (Year 1) } \\
\text { (j) "I was pleased to find out that drafts are not meant to be perfect but are a work in progress. I } \\
\text { realized that you have to start from a place where you don't want to be to get to where you } \\
\text { do want to be." (Year 2) }\end{array}$ \\
\hline $\begin{array}{l}\text { 6. The instructor } \\
\text { focused student } \\
\text { attention on the } \\
\text { assessment } \\
\text { rubric }\end{array}$ & $\begin{array}{l}\text { (k) "I thought I got everything on the rubric, but after she explained it, I realized she wanted it } \\
\text { more narrowed down, so you become more conscious to always look at the rubric." (Year 1) } \\
\text { (l) "It is really motivating to know that you are heading in the right direction-to be able to ask } \\
\text { about the assessment grid and to make sure you understand it-as all assessments are } \\
\text { marked according to this." (Year 2) }\end{array}$ \\
\hline
\end{tabular}

Note: This table includes testimony from a range of students in our sample drawn from the two modules

\section{Theme 3. Students' relationships with the instructor}

The students commented that the relational feed-forward meetings altered their perception of and relationship with the instructor. They believed the dialogue forged a closer bond between themselves and their instructor. Therefore, they seemed more able to approach their instructor and to continue to build the relationship over time:

During the meeting it wasn't just about the assignment, it was more like building a bond between us ... I feel like I am more connected to her. She's not just my teacher. She's like not "up there," but like someone I can go to. It made me feel she truly wants me to succeed. (Year 1)

I see her as more of a friendly person that I can talk to about things other than the assessment as the module goes on. (Year 2)

The conversation about work in progress felt personal to students, demonstrating that the instructor cared about them. The instructor became more "human" to most of the students and they felt more individualized in the eyes of their instructor. They commented:

The way she approached the discussion made me feel like she truly cared and wanted the best for me, so I felt supported. (Year 1)

I saw her as much more human, and kind of on my side. She treated me like I was not just a number on a piece of paper. I was an individual and she made me feel like that, as though she appreciated my efforts. (Year 2)

This sense of personal connection between student and instructor made some students want to perform well not just for themselves, but for their instructor, to reward the latter's time, effort, and sense of care. 
Theme 4. Students' assessment attitudes and behaviours

As the relational feed-forward clarified students' understanding of their assessment progress and key areas for improvement, it altered their behaviour in-task. They were motivated to take action and develop their work before final grading. They explained:

Right after the meeting I started to correct my work... I felt more motivated for the second submission because discovering what I could work on, how it could improve, just made me feel like I'm ready to do better. (Year 1 )

I understood much more what I needed to do to make my essay better. I really wanted to get on and make the changes. I was inspired to put more time in and to improve it. (Year 2)

In particular, some students commented about being more conscious of planning and organising their time, saying they would start assignments early, work methodically through drafts, and reflect upon their work in progress. As one first year student neatly summarized, "don't do everything the day before it's due."

Many students self-avowed to changing their future assessment behaviour, drafting work, and seeking instructor feedback:

I want to take more time to reflect and make changes to my work. There is a process of writing an essay, you don't just get to a great outcome in one attempt. (Year 2)

I'm going to try and write drafts next year and take these to my tutors or use them to ask questions. ... I think now that it's silly to hide from feedback. This is not helpful to me as a learner. (Year 2)

Through just one iteration of relational feed-forward we see students self-avowing to changed feedback attitudes and learning behaviours. They not only feel enabled emotionally, but they also recognize the benefits for improving academic outcomes:

I use feedback more. Usually, if I saw a comment, I would be like, "Oh okay, whatever." But now, I like actually look into it and see what it was that was good or bad because it helps me do something better. (Year 1)

I see it as allowing us to fulfil what we actually can do, rather than working with what you think you can do and then handing it in and be criticized. (Year 2)

The relational feed-forward raised self-efficacy for the majority of students with respect to the task in hand and future assessed work:

I am more confident going into other assignments. I now know what I need to change, what I need to improve upon, and what else I can do in the future to assure the same success. (Year 1)

Having the meeting I realized how useful feedback is to learning. I felt much more confident in myself about the essay, even realising that other assessments require a lot of work, not just trying to 
do them the night before, but really thinking about them, writing them, and wanting to get feedback to improve. (Year 2)

Overall, it was clear that relational feed-forward rendered assessment a valuable form of learning for the students:

I used to think we learnt in class and then we did assessments to see how far we had got. Now I see assessment as a way of finding out where we are early on, so I can make positive changes.

Assessment is actually a really good way to learn if you go out there and ask for feedback. (Year 2)

Consequently, many of the second-year students asked for feed-forward to come earlier in their learning journey so they could understand how to respond to instructor comments from the start of their undergraduate education.

Theme 5. The role of the instructor in managing feedback emotions

All students were keen for instructors to help them manage their emotions related to assessment. They believed this would bring out the best in them:

If the instructor just disregarded the way their students felt about certain assignments and how they did, then the student would just not care either. (Year 1)

Tutors should help us with the emotions related to assessment. Assessment is scary. It is about judgement and tutors have to be kind as well as fair in how they judge you. If they show you they care then you want to do well for them as well as for yourself. (Year 2)

The students offered ideas about what instructors could do to help them with the emotions they experience related to feedback. Their suggestions were built around instructors giving balanced critique and offering more personal feedback encounters. In addition to requesting more relational feed-forward on work in progress, they noted the potential benefits of informal chats before or after lectures, using office hours to answer specific questions, and running non-mandatory feedback days. For larger groups, they discussed screen-casting of personalized feedback for students who might record and send a response back to their instructor.

Theme 6. The impact of relational feed-forward on wellbeing

The students made clear that talking about feedback helped them to deal with their emotions, thereby promoting their wellbeing. They commented, for example:

Encountering my emotions purposefully via feedback dialogue can help promote my wellbeing because I think it's more personable... I'm not left without understanding what I can do next. (Year 1)

I didn't feel so alone with my work, with a tutor waiting to criticize it. I felt more like we were a team, trying to make me the best that I could be. This made me feel capable and strong, and not isolated and doubting myself... Being confident in yourself and being able to talk with your tutor definitely helps with wellbeing. (Year 2) 
Talking with the instructor appeared to remove the isolation and confusion often experienced by the students with respect to assessment feedback. It reduced or resolved problems before they festered and impacted upon their mental health.

\section{DISCUSSION}

The process of relational feed-forward promoted many elements of feedback literacy in our students, such as appreciating the purpose and value of feedback, judging work against a rubric, demonstrating volition and agency to act, and managing affect (Carless and Boud 2018). Dialogue during the instructor-student meetings supported the students to process and manage not just the cognitive (and metacognitive) aspects, but the affective aspects of their assessment tasks in a positive manner. As such, instructors would do well to demonstrate care for their students across the full assessment process, from the moment tasks are set, through planning, drafting, and feeding forward, to communication of summative grades (Kornhaber et al. 2016; Schwartz 2017). We clarify, however, that in asking instructors to openly attend to students' emotions through relational feedforward, we are not advocating for them to become counsellors. Rather, we are calling for an opening up to the possibilities that relational feed-forward can offer to enhance students' positive emotions and to support their wellbeing in relation to assessment, positioning instructor feed-forward as an act of care.

Our results demonstrated a clear evolution in the students' emotions during the feed-forward meetings. Students initially felt nervous and apprehensive to receive commentary on their work. As their encounter with feed-forward progressed, however, they reported more positive emotions of relief and happiness. Importantly, negative emotions arising from feedback did not dwell with these students as they had done previously with respect to written instructor commentary (Hill et al. $2021 \mathrm{~b}$ ). Rather, relational feed-forward helped these same students to feel positive about their work in real time, divorcing it from definitive comments about themselves (Hill and West 2020) and boosting their confidence to act on instructor commentary (Sadler 2010). The developmental nature of drafting, engaging in dialogue, and re-drafting was perceived as an active process of learning through assessment (Carless 2006; 2007).

There was some evidence for first- and second-year students differing in response to critique of their work. The first-year students sometimes experienced feedback more personally and were less able to adopt an agentic stance than the second years in responding to instructor commentary. This might be explained by first years being closer to teacher-pupil hierarchical relationships at school, encouraging an over-dependency on the instructor, and thus requiring time to curate and learn from feedback experiences (Robinson, Pope, and Holyoak 2013). By the second year, students seemed more able to regulate their emotions to be more proactive with instructor commentary.

In the one-on-one meetings, the instructors offered dialogue that was purposefully wellintentioned and receptive of student emotions, and they provided personalized guidance as to how the students' work could be improved. The instructors demonstrated to students that they mattered (Schwartz 2017), offering them encouragement and making them feel valued (Fong et al. 2019), respected (Zhou et al. 2021), and cared for (Kornhaber et al. 2016). Feeding forward in a low-stakes environment eased the anxiety that attended the judgement of work, helping some students overcome their fear of critique because they believed they could improve their work before final grading. Talking with the instructor about work in progress was valued by the students because it was 
personalized, supportive, and reassuring, eliciting largely positive emotions, increasing self-efficacy, and supporting wellbeing.

Our findings suggest that the relationship with the instructor is very important in encouraging students to seek feedback and wider support for their learning (agreeing with Middleton et al. 2020). The personalized nature of the meetings developed the social bonds between the instructor and the students, with the students reporting viewing instructors as far more approachable after the feed-forward dialogue. The students indicated that they felt greater volition to seek advice from the instructor in future, and to approach other academic staff for support.

With respect to the cognitive realm and supporting existing literature (Sadler 2010; Winstone et al. 2017), the students in our study were able, through relational interaction, to seek clarification and gain greater understanding of the meaning of instructor commentary. The students often referred to geographical metaphors such as knowing where they were with their work and establishing if they were going in the right direction. Gaining feed-forward in-task thereby allowed them to discover if they were tackling the assignments appropriately. This motivated them because they had a clearer idea of the task and instructor expectations (related to standards presented in the rubric), where they were in their learning, and where they were going (Hill and West 2020; Orsmond et al. 2013).

The relational feed-forward meetings can be viewed as borderland spaces of learning (Hill et al. 2016; 2019). These spaces are liminal, foregrounding a process of becoming. The dynamism of work in progress can generate discomfort and uncertainty for students (and also for the instructor) (Felten 2011). Many of the students in our study felt anxious and confused initially by the emerging re-formulations in their ways of thinking and doing, but the dialogue with the instructor helped them to develop with immediacy more positive feelings and actions. Eventually, engaging with instructors in the pedagogic borderland can offer students new ways of thinking and practising. Our students self-avowed to their new learning behaviours carrying forward into future work, increasing their selfefficacy as they believed more strongly in their capabilities to accomplish similar assignments in future (Ritchie 2016). Their academic buoyancy (Middleton et al. 2020), the ability to cope with ongoing setbacks in academic life, seemed to be enhanced.

The relational feed-forward dialogue began to dissolve the teacher-student contradiction (Freire 1970), with instructors using questioning to draw out understanding from students rather than viewing themselves as experts and narrating changes to draft work. This more equal relationship reduced the tensions inherent in the interpretations between two people of different levels of power and hierarchical status. Each student was met wherever they were on their assessment journey and they were motivated and supported to travel as far as they could. Such open acknowledgment of unfinishedness (Freire 1998), of the messiness that lies behind completed work, supports development of a growth mindset (Dweck 2006). The students came to see their assignments as work in progress rather than a definitive statement of their worth. Through relational feed-forward, instructor commentary was viewed as a fulcrum for progress and developing cognitively, metacognitively, and affectively. The students were keen for this dialogue to continue throughout their undergraduate journey as they believed it contributed to their wellbeing, helping them to work better and achieve more positive outcomes.

\section{IMPLICATIONS FOR PRACTICE}

Given that assessments are a regular feature of higher education courses, and the judgemental nature of associated feedback can lead to negative student emotions, attitudes, and behaviours, it is 
incumbent upon us as instructors to explore academic strategies and pedagogies that might mitigate against negative emotions damaging students' motivation, self-efficacy, and wellbeing.

\section{Embedding relational encounters in first-year and later assessments}

As instructors, we might ask ourselves whether we need to reconceive our approach to assessment, particularly in the first year of undergraduate studies when students are particularly vulnerable to critique (Hill et al. 2021b). At entry level, we often have high student numbers, which can lead to the adoption of generic written feedback or annotation of assessment rubrics. But students in their first year of study are trying to establish what assessment and feedback means for them at university compared with their experiences at school. This is the time to shape students' conceptions and to prepare them for the receipt of instructor commentary, the emotional responses that are likely to accompany it, and how they might act effectively to improve their work. We recommend that students are prepared early in their university learning experience with information about feedback theory and practice, from pre-arrival information, through induction, to development over the first year and onward. Alongside this, meetings with personal tutors and use of peer support networks, offering positive emotional reassurance, might also help first-year students gain confidence in a university environment.

An important question is how we can scale up relational feed-forward from the class sizes of 30-40 students reported here. One approach is to develop first-year curricula specifically around assessment, in which students are taught feedback literacy as an intended learning outcome. This might mean dividing larger numbers of students amongst a greater number of instructors (e.g. a ratio of 20:1) to undertake assessment, with a clear aim of building assessment skills and feedback recipience. For a core module, a single staged assignment with a feed-forward meeting might replace multiple smaller summative assignments, essentially requiring comparable instructor resource.

Personal tutoring might be absorbed into this module to offer a larger resource envelope and this also ensures that conversations between academic staff and students are meaningful as they are directly relevant to ongoing assessment. Careful attention must be paid to instructor resource, profiling workload across course teams and ensuring labour-intensive relational feed-forward activities are used strategically early in curricula and individual teaching units.

The value of assessment dialogue can come from many activities over the duration of a course, both within class time and extending beyond it (Winstone and Carless 2020). For example, an extended induction period in the first year of study might focus on academic skills and reflective and discursive approaches to feedback. Seminars can be used to direct students to reflect on written feedback they have received and to discuss it with their instructor and/or peers. Oral presentations and collaborative projects are good vehicles for engaging students in carefully supported peer-to-peer dialogue around the strengths and weaknesses of work in progress. The personalized nature of feedforward can be replicated by screen-casting instructor commentary on an exemplar piece of work and enabling students to view this in their own time. Allowing students to ask the instructor questions after viewing the screencast encourages true dialogue to be established. As a final example, a practical form of interaction that can be used with any assignment, whatever the class size, is the use of interactive coversheets. On these sheets, students self-evaluate their assignment submissions against the rubric, summarising how previous feedback has informed their work, and requesting specific feedback. Instructors respond as they mark the work, generating dialogue within conventional module schedules. The key consideration is to support the development of students' autonomous learning and to weight curricular design in later years towards specific instructor commentary, 
supported by a greater proportion of student-generated dialogue and peer-to-peer feedback. In this way, the students' own abilities and confidence for self-directed learning are gradually strengthened as they rely more on their own (and peer) resources and less on instructor support.

\section{Delivery of emotionally resonant feed-forward}

The manner in which instructors deliver their assessment commentary is critical to achieving positive cognitive and affective outcomes in students. Here we highlighted the purposefully open, supportive, and empathetic nature of the relational feed-forward meetings. These facets were drawn from the work of Carl Rogers within the field of humanistic psychology. Rogers (1959) postulated that for a person to develop, they require an environment that is genuine (open and self-disclosing), accepting (offers unconditional positive regard), and empathetic (receptive). Transferred to higher education, this means it is crucial for instructors to demonstrate patience and understanding with respect to students' draft work, not withdrawing positive regard if a student has made mistakes. Instructors might share their own experiences of learning from critical feedback via scholarly peer review. Offering unconditional positive regard in a low-stakes environment enables students to experiment and learn from their mistakes. As such, we see the early stages of selfactualization in our students (Maslow 1962) as they both recognize and believe they can achieve their potential through the assessment task. This leads to them experiencing positive emotions and a sense of wellbeing.

Through our participation as instructors in relational feed-forward, from interpreting the responses of our students in terms of effective relational interactions and building on the implications we noted in the earlier phase of our research (figure 1 in Hill et al. 2021b), we synthesize the key characteristics of emotionally resonant relational feed-forward in table 3.

\section{Table 3. Characteristics of emotionally resonant relational feed-forward meetings}

\section{Key characteristics}

1. Be prepared for each meeting, having reviewed the strengths and weaknesses of the work and the key points for action.

2. Be warm and welcoming from the outset—consider the physical context, your body language, your tone of voice, and your forms of verbal expression.

3. Clarify the assessment process and the purpose of dialogic feed-forward within it.

4. Express feedback carefully, balancing positive and negative comments, and beginning with a positive point. Highlight key developmental features for students to focus on.

5. Relate your comments clearly to the work in progress, rather than making them about the student.

6. Make the students feel valued and respected for their efforts, showing them that you care.

7. Reassure the students that they are capable of making the changes that you suggest.

8. Share personal responses to critique of your scholarship—normalize emotions and intellectual stumbling blocks. Explain what you do to move forward confidently with your work. 
9. Support your students to construct an action plan before they leave the meeting.

10. Check the students are okay as they leave the meeting and reassure them that they can contact you with further specific questions.

\section{CONCLUSION}

Our research has highlighted a positive role for instructor-student relational feed-forward in dissipating negative emotions experienced by students related to summative assessment. If, as instructors, we demonstrate care and reassurance through relational feed-forward in the students' earliest encounters with assessment, we might enable increasingly productive and self-regulating learning attitudes and behaviours, supporting mental health and wellbeing.

Bearing in mind that COVID-19 was declared a global pandemic during our research and has continued to curtail on-campus teaching and learning activities, we might ask what the future holds for the practice of relational feed-forward. We can only hypothesize about this as our data were collected pre-pandemic. We believe, however, that "face-to-face" dialogue can be undertaken effectively online using a virtual learning environment if it is designed carefully into learning (following Coomey and Stephenson 2001). Our students indicated that online dialogue would be valuable for their learning and there is anecdotal evidence from the UK that personal tutor sessions that have taken place remotely during social distancing have been well received by undergraduate students, if not preferred by some, because of their flexibility. It will become more important than ever to deliver caring pedagogies for our students under the stress of global pandemics. Integrating relational feed-forward progressively into our curricula, on campus or online, might offer an effective means to promote positive student emotions, building their motivation, self-efficacy, and selfregulation, and supporting their wellbeing. By adopting a relational approach to feedback, embedded in an institutional partnership approach, we might support more of our students to reach their academic potential, whatever constraints are imposed on their physical learning contexts.

\section{ACKNOWLEDGMENTS}

This project was part of the ISSOTL International Collaborative Writing Group initiative, whose members met in Atlanta, Georgia (US) in October 2019. The authors wish to express their gratitude for the excellent and sustained support offered by the leaders of the ICWG 2019: Aysha Divan, Phillip Motley, and Lauren Scharff.

Jennifer Hill, PhD, is professor of higher education pedagogies and head of learning and teaching innovation at the University of Gloucestershire (GBR). https://orcid.org/0000-0002-0682-783X.

Kathryn Berlin, PhD, is an associate professor and program director for health sciences at Indiana University Purdue University Indianapolis, Indiana (USA). https://orcid.org/0000-0003-4607-5326.

Julia Choate, PhD, is an associate professor and director of physiology education at Monash University, Melbourne (AUS). https://orcid.org/0000-0002-3016-698X.

Lisa Cravens-Brown is associate vice chair for instruction in the department of psychology at The Ohio State University, Columbus Ohio (USA). 
Lisa Mckendrick-Calder, MN, is an assistant professor in the department of nursing sciences at MacEwan University in Edmonton, Alberta (CAN). https:///orcid.org/0000-0002-3261-7174.

Susan Smith, PhD, is a professor in teaching and learning and associate director of the Centre for Learning and Teaching at Leeds Beckett, University, Leeds (GBR). http://orcid.org/0000-0001-5803-4332.

\section{REFERENCES}

Ajjawi, Rola, and David Boud. 2018. "Examining the Nature and Effects of Feedback Dialogue." Assessment and Evaluation in Higher Education 43: 1106-19. https://doi.org/10.1080/02602938.2018.1434128.

Auerbach, Randy P., Phillipe Mortier, Ronny Bruffaerts, Jordi Alonso, Corina Benjet, Pim Cuijpers, Koen Demyttenaere, David. D. Ebert, Jennifer G. Green, Penelope Hasking,

Elaine Murray, Matthew K. Nock, Stephanie Pinder-Amaker, Nancy A. Sampson, Dan J. Stein, Gemma Vilagut, Alan M. Zaslavsky, Ronald C. Kessler, and the WHO WMH-ICS Collaborators. 2018. "WHO World Mental Health Surveys International College Student Project: Prevalence and Distribution of Mental Disorders." Journal of Abnormal Psychology 127: 623-38. https://doi.org/10.1037/abn0000362.

Barnett, Ronald. 2007. A Will to Learn: Being a Student in an Age of Uncertainty. Maidenhead: Open University Press.

Boud, David, and Elizabeth Molloy. 2013. "Rethinking Models of Feedback for Learning: the Challenge of Design." Assessment and Evaluation in Higher Education 38: 698-712. https://doi.org/10.1080/02602938.2012.691462.

Braun, Virginia, and Victoria Clarke. 2013. Successful Qualitative Research: A Practical Guide for Beginners. London: SAGE Publications.

Carless, David. 2006. "Learning-Oriented Assessment: Principles and Practice." Assessment and Evaluation in Higher Education 31: 395-98. https://doi.org/10.1080/02602930600679043.

Carless, David. 2007. "Learning-Oriented Assessment: Conceptual Bases and Practical Implications." Innovations in Education and Teaching International 44: 57-66. https://doi.org/10.1080/14703290601081332.

Carless, David. 2020. “Longitudinal Perspectives on Students' Experiences of Feedback: A Need for TeacherStudent Partnerships." Higher Education Research and Development 39: 425-38. https://doi.org/10.1080/07294360.2019.1684455.

Carless, David, and David Boud. 2018. "The Development of Student Feedback Literacy: Enabling Uptake of Feedback." Assessment and Evaluation in Higher Education 43: 1315-25. https://doi.org/10.1080/02602938.2018.1463354.

Carless, David, Diane Salter, Min Yang, and Joy Lam. 2011. "Developing Sustainable Feedback Practices." Studies in Higher Education 36: 395-407. https://doi.org/10.1080/03075071003642449.

Carter, Margaret A., Paul Pagliano, Abraham Francis, and Marcia Thorne. 2017. "Australian University Students and Mental Health: Viewpoints from the Literature." International Journal of Innovation, Creativity and Change 3: 1-5.

Coomey, Marion, and John Stephenson. 2001. "Online Learning: It is All About Dialogue, Involvement, Support and Control-According to the Research." Teaching and Learning Online: Pedagogies for New Technologies, edited by John Stephenson, 37-52. London: Routledge.

Denzin, Norman K., and Yvonna S. Lincoln. 2011. The SAGE Handbook of Qualitative Research, no. 4. Thousand Oaks, CA: SAGE Publications.

Department of Education and Early Childhood Development (DEECD). 2010. The Effectiveness of Student Wellbeing Programs and Services. Accessed October 26, 2020. https://www.parliament.vic.gov.au/papers/govpub/VPARL2006-10No270.pdf.

Dweck, Carol S. 2006. Mindset: The New Psychology of Success. New York: Ballantine Books.

Felten, Peter. 2011. "From the Advisory Board: Monet Moments and the Necessity of Productive Disruption." Teaching \& Learning Together in Higher Education 1: 1-2. https://repository.brynmawr.edu/tlthe/vol1/iss2/1.

Felten, Peter. 2013. "Principles of Good Practice in SoTL." Teaching \& Learning Inquiry 1: 121-25. https://doi.org/10.20343/teachlearninqu.1.1.121.

Ferguson, Donna. 2017. “The Rise in Student Mental Health Problems—I Thought My Tutor Would Say Deal 
With It." The Guardian, August 29. Accessed October 26, 2020.

https://www.theguardian.com/education/2017/aug/29/the-rise-in-student-mental-healthproblems-i-thought-my-tutor-would-say-deal-with-it.

Fong, Carlton J., Erika A. Patall, Ariana C. Vasquez, and Sandra Stautberg. 2019. "Meta-Analysis of Negative Feedback on Intrinsic Motivation." Educational Psychology Review 31: 121-62. https://doi.org/10.1007/s10648-018-9446-6.

Forsythe, Alex, and Sophie Johnson. 2017. "Thanks, But No-Thanks for the Feedback." Assessment and Evaluation in Higher Education 42: 850-59. https://doi.org/10.1080/02602938.2016.1202190.

Fredrickson, Barbara L., and Thomas Joiner. 2002. "Positive Emotions Trigger Upward Spirals Toward Emotional Wellbeing." Psychological Science 13: 172-75. https://doi.org/10.1111/1467-9280.00431.

Freire, Paulo. 1970. Pedagogy of the Oppressed. New York, NY: Continuum.

Freire, Paulo. 1998. Pedagogy of Freedom: Ethics, Democracy and Civic Courage. Lanham, MD: Rowman and Littlefield.

Hattie, John, and Helen Timperley. 2007. "The Power of Feedback." Review of Educational Research, 77, 81 112. https://doi.org/10.3102/003465430298487.

Hill, Jennifer, and Harry West. 2020. "Improving the Student Learning Experience Through Dialogic FeedForward Assessment." Assessment and Evaluation in Higher Education 45: 82-97. https://doi.org/10.1080/02602938.2019.1608908.

Hill, Jennifer, Greg Thomas, Anita Diaz, and David Simm. 2016. "Borderland Spaces for Learning Partnership: Opportunities, Benefits and Challenges." Journal of Geography in Higher Education 40: 375-93. https://doi.org/10.1080/03098265.2016.1144728.

Hill, Jennifer, Helen Walkington, and Pauline Kneale. 2019. "Borderland Spaces: Moving Towards SelfAuthorship." Reframing Space for Learning: Excellence and Innovation in University Teaching, edited Tim Bilham, Claire Hamshire, Mary Hartog and Martina A. Doolan, 88-101. London: UCL/loE Press.

Hill, Jennifer, Ruth L. Healey, Harry West, and Chantal Déry. 2021a. “Pedagogic Partnership in Higher Education: Encountering Emotion in Learning and Enhancing Student Wellbeing." Journal of Geography in Higher Education, 45: 167-85. https://doi.org/10.1080/03098265.2019.1661366.

Hill, Jennifer, Kathy Berlin, Julia Choate, Lisa Cravens-Brown, Lisa McKendrick-Calder, and Susan Smith. 2021 b. "Exploring the Emotional Responses of Undergraduate Students to Assessment Feedback: Implications for Instructors." Teaching \& Learning Inquiry 9: 294-316.

Kim, Eun Jung, and Kyeong Ryong Lee. 2019. “Effects of an Examiner's Positive and Negative Feedback on Self-Assessment of Skill Performance, Emotional Response, and Self-Efficacy in Korea: A QuasiExperimental Study." BMC Medical Education 19, article no. 142: 1-7. https://doi.org/10.1186/s12909019-1595-x.

Kornhaber, Rachel, Kenneth Walsh, Red Duff, and Kim Walker. 2016. “Enhancing Adult Therapeutic Interpersonal Relationships in the Acute Health Care Setting: An Integrative Review." Journal of Multidisciplinary Healthcare 9: 537-46. https://doi.org/10.2147/JMDH.S116957.

Maslow, Abraham H. 1962. Toward a Psychology of Being. Princeton: D. Van Nostrand Company.

Meyer, Debra K., and Julianne C. Turner. 2002. "Discovering Emotion in Classroom Motivation Research." Educational Psychologist 37: 107-14. https://doi.org/10.1207/S15326985EP3702 5.

Middleton, Tristan, Adeela ahmed Shafi, Richard Millican, and Sian Templeton. 2020. "Developing Effective Assessment Feedback: Academic Buoyancy and the Relational Dimensions of Feedback." Teaching in Higher Education. https://doi.org/10.1080/13562517.2020.1777397.

Nicol, David. 2010. “From Monologue to Dialogue: Improving Written Feedback Processes in Mass Higher Education." Assessment and Evaluation in Higher Education 35: 501-17. https://doi.org/10.1080/02602931003786559.

Nicol, David J., and Debra Macfarlane-Dick. 2006. "Formative Assessment and Self-Regulated Learning: A Model and Seven Principles of Good Feedback Practice." Studies in Higher Education 31: 199-218. https://doi.org/10.1080/03075070600572090.

Orsmond, Paul, Stephen J. Maw, Julian R. Park, Stephen Gomez, and Anne C. Crook. 2013.“Moving Feedback Forward: Theory to Practice." Assessment and Evaluation in Higher Education 38: 240-52. https://doi.org/10.1080/02602938.2011.625472.

Ortlipp, Michelle. 2008. "Keeping and Using Reflective Journals in the Qualitative ResearchProcess." The Qualitative Report 13:695-705. https://nsuworks.nova.edu/tar/vol13/iss4/8/.

Pitt, Edd, and Lin Norton. 2017. "'Now That's the Feedback I Want!' Students' Reactions to Feedback on 
Graded Work and What They Do With it." Assessment and Evaluation in Higher Education 42: 499-516. https://doi.org/10.1080/02602938.2016.1142500.

Reimann, Nicola, lan Sadler, and Kay Sambell. 2019. "What's in a Word? Practices Associated With 'Feedforward' in Higher Education." Assessment and Evaluation in Higher Education 44: 1279-90. https://doi.org/10.1080/02602938.2019.1600655.

Ritchie, Laura. 2016. Fostering Self-Efficacy in Higher Education Students. London: Palgrave.

Robinson, Sarita, Debbie Pope, and Lynda Holyoak. 2013. "Can We Meet Their Expectations? Experiences and Perceptions of Feedback in First Year Undergraduate Students." Assessment and Evaluation in Higher Education 38: 260-72. https://doi.org/10.1080/02602938.2011.629291.

Rogers, Carl R. 1959. "A Theory of Therapy, Personality and Interpersonal Relationships as Developed in the Client-Centered Framework." Psychology: A Study of a Science. Vol. 3: Formulations of the Person and the Social Context, edited by Sigmund Koch, 184-256. New York: McGraw Hill.

Ryan, Tracii, and Michael Henderson. 2018. “Feeling Feedback: Students' Emotional Responses to Educator Feedback." Assessment and Evaluation in Higher Education 43: 880-92. https://doi.org/10.1080/02602938.2017.1416456.

Sadler, D. Royce. 2010. "Beyond Feedback: Developing Student Capability in Complex Appraisal." Assessment and Evaluation in Higher Education 35: 535-50. https://doi.org/10.1080/02602930903541015.

Schwartz, Harriet L. 2017. "Sometimes it's About More Than the Paper: Assessment as Relational Practice." Journal on Excellence in College Teaching 28: 5-28. https://eric.ed.gov/?id=EJ1150238.

Small, Felicity, and Kath Attree. 2016. “Undergraduate Student Responses to Feedback: Expectations and Experiences." Studies in Higher Education 41: 2078-94. https://dx.doi.org/10.1080/03075079.2015.1007944.

Steen-Utheim, Anna, and Anne L. Wittek. 2017. "Dialogic Feedback and Potentialities for Student Learning." Learning, Culture and Social Interaction 15: 18-30. https://doi.org/10.1016/j.lcsi.2017.06.002.

Strauss, Anselm, and Juliet M. Corbin. 1994. "Grounded Theory and Methodology." In Handbook for Qualitative Research, edited by Norman K. Denzin and Yvonna S. Lincoln, 273-85. London: SAGE Publications.

Winstone, Naomi, and David Carless. 2020. Designing Effective Feedback Processes in Higher Education. A Learning-focussed Approach. Abingdon: Routledge.

Winstone, Naomi E., Robert A. Nash, James Rowntree, and Michael Parker. 2017. "'It'd Be Useful, but I Wouldn't Use it': Barriers to University Students' Feedback Seeking and Recipience." Studies in Higher Education 42: 2026-41. https://doi.org/10.1080/03075079.2015.1130032.

Yang, Min, and David Carless. 2013. "The Feedback Triangle and the Enhancement of Dialogic Feedback Processes." Teaching in Higher Education 18: 285-97. https://doi.org/10.1080/13562517.2012.719154.

Zhou, Jiming, Phillip Dawson, Joanna Hong-Meng Tai, and Margaret Bearman. 2021. "How Conceptualizing Respect Can Inform Feedback Pedagogies." Assessment and Evaluation in Higher Education 46: 68-79. https://doi.org/10.1080/02602938.2020.1733490. 


\section{APPENDIX 1: SMALL GROUP SEMI-STRUCTURED INTERVIEW SCHEDULE}

\section{Interview 2: After receipt of instructor relational feed-forward}

1. Have you received face-to-face/verbal assessment feedback from an instructor in the past?

a. If this is a new experience, how have you normally received assessment commentary from your instructor?

2. Thinking about this course, in the time between submitting your assessment and having the dialogue with your instructor, what emotions did you experience whilst awaiting instructor commentary? Why did you feel like this?

3. What emotions did you experience in the meeting, as you received the instructor comments on your work?

a. Were there aspects of the meeting that impacted your feelings/emotions?

4. What emotions did you experience after receiving the instructor comments on your work? Why did you feel like this?

- Did you feel better/worse about your work and/or yourself?

- How long did this change in your feelings take?

- Did the emotions impact upon your next steps with this work?

5. Did your emotions change because you discussed the assessment comments with your instructor? If so, can you tell me how and in what way your emotions changed? If not, can you tell me why you think they did not change?

- What was it about the interaction with your instructor that caused your emotions to change?

- Did you find this interaction useful in bringing your emotions to light? If so, why?

6. Did the discussion with your instructor about your assessed work alter your attitude towards improving it before final submission? Was this related to your emotions?

7. Did the discussion with your instructor about your assessed work alter your learning behaviour with respect to the assessment task? Was this related to your emotions?

8. Do you feel differently about your instructor after this dialogic process—and why?

9. Looking back at this course, did your emotional response to instructor assessment commentary change over the duration of the course? If yes, why do you think this is?

10. What did you do to manage your assessment-related emotions?

a. Do you think the process of talking with your instructor helped you to manage your emotions in a positive way? 
11. Do you think the process of talking with your instructor helped you with your learning on the course? If so, how?

- Specifically, did it help improve motivation, self-confidence, self-esteem, planning and organizing your academic work?

- Did it alter your relationship with the instructor?

12. Is it important that we, as instructors, help you with the emotions related to assessment?

- What can we do to make the emotional side of receiving commentary on your assessed work better for you?

- What would be a good situation in terms of helping you with the emotions you experience as you receive instructor commentary on your work?

13. Do you think that encountering your emotions purposefully via feedback dialogue can help to promote your wellbeing? 